\title{
BMJ open What are the factors associated with HIV testing among male injecting and non-injecting drug users in Lashio, Myanmar: a cross-sectional study
}

To cite: Saw YM, Yasuoka J Saw TN, et al. What are the factors associated with HIV testing among male injecting and non-injecting drug users in Lashio, Myanmar: a crosssectional study. BMJ Open 2013;3:e002747.

doi:10.1136/bmjopen-2013002747

- Prepublication history for this paper is available online. To view these files please visit the journal online (http://dx.doi.org/10.1136/ bmjopen-2013-002747).

Received 2 May 2013

Revised 11 April 2013

Accepted 7 May 2013

This final article is available for use under the terms of the Creative Commons Attribution Non-Commercial 2.0 Licence; see http://bmjopen.bmj.com

${ }^{1}$ Department of Community and Global Health, Graduate School of Medicine, The University of Tokyo, Tokyo, Japan

${ }^{2}$ Department of Public Health, School of Public Health and Health Sciences, University of Massachusetts Amherst, Amherst, Massachusetts, USA

${ }^{3}$ Department of Preventive and Social Medicine, The University of Medicine 2, Yangon, Myanmar

Correspondence to Dr Junko Yasuoka; jyasuoka@post.harvard.edu

\section{ABSTRACT}

Objectives: HIV testing is an effective intervention for reducing HIV risk and providing information on HIV status. However, uptake of HIV testing is a major challenge within the drug-using population due to the stigma and discrimination associated with their illegal drug use behaviours. This study thus aimed to identify factors associated with HIV testing among injecting drug users (IDUs) and non-injecting drug users (NIDUs) in Lashio, Myanmar.

Design: A cross-sectional study was conducted from January 2010 to February 2010.

Setting: This study was carried out in Lashio city, Northern Shan State, Myanmar.

Participants: In total, 158 male IDUs and 210 male NIDUs were recruited using a respondent-driven sampling method.

Primary outcome measures: Proportion of both drug users who were ever tested for HIV and factors associated with HIV testing.

Results: Approximately $77 \%$ of IDUs and $46 \%$ of NIDUs were ever tested for HIV. The multivariate analysis revealed that having ever received drug treatment was positively associated with HIV testing among both IDUs (adjusted OR (AOR) 13.07; 95\% $\mathrm{Cl} 3.38$ to 50.53) and NIDUs (AOR 3.58; $95 \% \mathrm{Cl} 1.38$ to 9.24). IDUs who were married (AOR $0.24 ; 95 \% \mathrm{Cl} 0.06$ to 0.94 ) and who injected at least twice daily (AOR $0.30 ; 95 \% \mathrm{Cl} 0.09$ to 0.97 ) were less likely to undergo HIV testing. Among NIDUs, those who belonged to Shan (AOR $0.30 ; 95 \% \mathrm{Cl}$ 0.11 to 0.84 ) or Kachin (AOR $0.30 ; 95 \% \mathrm{Cl} 0.10$ to 0.87 ) ethnicities were less likely to test for HIV.

Conclusions: IDUs and NIDUs who have received drug treatment are more likely to test for HIV. Integrating HIV testing into drug treatment programmes alongside general expansion of HIV testing services may be effective in increasing HIV testing uptake among both IDUs and NIDUs in the Northern Shan State of Myanmar.

\section{INTRODUCTION}

Myanmar is one of the countries hardest hit by the HIV epidemic in South-East Asia.

\section{ARTICLE SUMMARY}

Article focus

- To identify factors associated with HIV testing among injecting drug users (IDUs) and noninjecting drug users (NIDUs) in Lashio, Myanmar.

Key messages

- IDUs were more likely than NIDUs to have been tested for HIV.

- HIV testing rates were especially low among both IDUs and NIDUs engaging in risk behaviours.

- IDUs and NIDUs would benefit from integrating HIV testing services into drug treatment services.

Strengths and limitations of this study

- The first look at HIV testing that covered both IDUs and NIDUs.

- Respondent-driven sampling was used to recruit participants.

- HIV testing was self-reported by drug users.

- Results may not be generalised to drug users in other cities of Myanmar.

According to the Joint United Nations Programme on AIDS (UNAIDS), approximately 240000 people were living with HIV/ AIDS at the end of 2011, and HIV prevalence was $0.5 \%$ within Myanmar's adult population. ${ }^{1}$ Injecting drug use is a primary mode of HIV transmission in the country. The estimated number of drug users in 2008 was $300000-400000$, of whom 90000 150000 were injecting drug users (IDUs)..$^{23}$ HIV prevalence among IDUs was $21.9 \%$ in 2011. ${ }^{1}$ To tackle this problem, Myanmar has actively promoted condom use, improved the management of sexually transmitted infections (STIs), and made access to HIV testing and counselling services more widespread.

HIV testing is a highly cost-effective intervention for reduction of HIV risk and transmission. ${ }^{4}$ Early discovery of HIV infection in individuals is essential to provide HIV-related 
care and treatment, and to prevent further spread of the disease to others. In addition, HIV testing and counselling can increase knowledge of HIV/AIDS, reduce risky sexual and drug use behaviours, and prevent other STIs. ${ }^{5-9}$ It is therefore important to encourage IDUs and non-injecting drug users (NIDUs) to be tested for HIV infection.

In Myanmar, both the government and international non-governmental organisations (INGOs) have been providing a variety of HIV testing services including referrals and pretest and post-test counselling. ${ }^{10}$ By the end of 2006, 289 service delivery points were providing HIV testing services in Myanmar-53\% implemented through the government sector, and 47\% through INGOs. ${ }^{11}$ However, HIV testing uptake has been a major challenge within the drug using populations. Owing to the varying levels of stigma and discrimination associated with drug use and its illegality, access to mainstream public health services is often limited in the drug using population. ${ }^{12}$ In Myanmar, drug treatment, including methadone maintenance treatment (MMT), is provided through government-run medical facilities, and HIV testing is not a compulsory service in the treatment.

Despite the critical importance of these population subgroups to HIV prevention and treatment efforts, only limited information is available on the characteristics of both IDUs and NIDUs undergoing HIV testing in Myanmar. Therefore, the purpose of this study was to identify the characteristics of IDUs and NIDUs undergoing HIV testing, and to identify factors associated with testing uptake in Lashio Township, Northern Shan State, Myanmar.

\section{METHODS}

\section{Study design and area}

A cross-sectional study was conducted in Lashio city in the Northern Shan State of Myanmar, which was located close to the Chinese border. Data were collected between January 2010 and February 2010. Lashio is one of the townships in Myanmar recommended as a priority focus for HIV interventions due to the high HIV prevalence among IDUs- $48.5 \%$ in $2007 .{ }^{13}$ Information on HIV prevalence among NIDUs, meanwhile, is not available in Myanmar.

\section{Study participants}

In this study, IDUs were defined as individuals having visible signs of injection, as confirmed by medical personnel in a private setting, and/or those who had injected drugs in the last 6 months. NIDUs were defined as those with no history of injecting drug use and those who had used drugs by a non-injecting route in the last 6 months. Study participants were recruited using the following criteria: (1) male IDU or male NIDU, (2) aged 18 years or older, (3) had used drugs in the last 6 months, (4) exhibiting no withdrawal symptoms and not under the influence of drugs at the time of interview, and (5) able to speak the Myanmar language.

A total of 176 IDUs and 217 NIDUs were ultimately enrolled in the study. Of them, 18 IDUs and 7 NIDUs were excluded from analysis because of incomplete responses. The remaining participants, 158 IDUs and 210 NIDUs, were included in the data analysis.

\section{Sampling method}

A respondent-driven sampling method was used to recruit participants as an approach generally regarded as effective for reaching hidden populations. ${ }^{14}$ The method uses dual incentives and a structured coupon disbursement process of 'peer referral' to reduce typical flaws and biases inherent in sampling of hidden populations. The first-round respondents, also known as 'seeds', were recruited from the pool of service-recipients at a local drop-in centre (DIC). From three seeds (two IDUs and one NIDU), a total of 174 IDUs and 216 NIDUs (not including seeds) were recruited who met the study criteria. The recruitment process did not distinguish between IDUs and NIDUs. Both IDUs and NIDUs were allowed to recruit any friends who used drugs by either means of administration. Distribution of coupons was terminated when the target sample size was attained. The successfully recruited participant was then provided with three coupons with serial numbers and instructions were given for passing those coupons to peers who were currently using drugs. Coupons were given a 2-week expiration date. The second respondent was also recruited in the same way.

All respondents recruited in this manner received an information, education and communication (IEC) pack that included two condoms with gel packs along with an incentive of 2000 Kyats (US\$ 2.5) as compensation for their time and travel. The respondents were eligible to receive a secondary incentive if recruits referred through them showed up at study sites to participate within the expiration period designated on their recruitment coupons. The secondary incentive was 500 Kyats (US\$0.5) per recruitment.

\section{Measures}

The dependent variable was if the respondent had ever tested for HIV. Specific HIV testing behaviour-related variables included ever having undergone an HIV test, HIV testing frequency, date of last HIV testing and site of last HIV testing. The independent variables were sociodemographic characteristics, drug use, sexual history, HIV testing behaviours and health service utilisation behaviours. $^{13}{ }^{15}$ Assessed sociodemographic variables included age (IDUs $\leq 29$-year-old vs >29-year-old and NIDUs $\leq 25$-year-old vs $>25$-year-old), marital status (single vs married vs divorced/widowed), race/ethnicity (Burma vs Shan vs Kachin vs Other), educational background ( primary/no formal education vs secondary education vs high school or above), employment 
(non-regular job vs regular job) and Lashio residence status (migrant vs resident).

Variables on drug use and sexual behaviours included type of illicit drug use, route of administration for drug use, frequency of injecting drug use, unsafe injecting practice (receptive or distributive syringe sharing; yes vs no), poly drug use (yes vs no), disclosure of sexual orientation (heterosexual vs bisexual/homosexual), having more than one partner (yes vs no) and history of female sex worker visit (yes vs no). Variables regarding health services utilisation included ever undergoing drug rehabilitation treatment (yes vs no), ever registered as a drug user (yes vs no) and ever convicted for drug-related crimes (yes vs no). All variables were measured for the last 6 months, unless otherwise stated.

The contents of the study questionnaire were adapted from several different studies previously conducted in Myanmar. The sociodemographic characteristics, drug use behaviour and health service utilisation-related questions were adapted from the rapid assessment and response on drug use and from the HIV Survey of the Asian Harm Reduction Network, Myanmar. ${ }^{15}$ Sexual behaviour and HIV testing behaviour-related questions were adapted from the Behavioral Surveillance Survey (BSS) Questionnaire of the Ministry of Health, Myanmar. ${ }^{13}$ Pretesting of the full questionnaire used in this study was carried out prior to data collection in Lashio with 20 IDUs and 20 NIDUs.

\section{Data collection}

After obtaining written informed consent from each participant, the lead researcher and six trained interviewers conducted interviews towards data collection. Participants were interviewed individually for 30-40 min in a private setting. Most interviews were conducted at a DIC. The research team also went to various field sites (shooting gallery, drug users' homes, cemetery, etc) to recruit participants who were willing to participate in the study but did not want to come to the DIC.

\section{Data analysis}

Data were coded and entered using the Statistical Package for the Social Sciences, SPSS V.16 (SPSS Inc, Chicago, Illinois, USA) for all analyses. Data analysis was carried out separately for IDUs and NIDUs. Descriptive statistics and $\chi^{2}$ tests were used to compare participants' background characteristics. Bivariate analyses were initially conducted to examine factors associated with HIV testing. Finally, all covariates were simultaneously entered into the multiple regression model to calculate adjusted ORs (AORs), 95\% CIs and corresponding $\mathrm{p}$ values.

\section{Ethical considerations}

This study protocol was approved by the Research Ethics Committee of the Graduate School of Medicine, the University of Tokyo, Tokyo, Japan and by the Institutional Ethical Review Committee of the Department of Medical
Research (Lower Myanmar), Ministry of Health, Yangon, Myanmar. The objectives of the study were made clear to respondents before their voluntary participation, and individual written informed consent was obtained from all participants. Each participant was allowed to withdraw from the study at any time. Confidentiality of the entire data set was maintained at all stages of data collection and analysis.

\section{RESULTS}

\section{Sociodemographic and drug use characteristics}

Of the 368 respondents, 158 were IDUs and 210 were NIDUs (table 1 ). The mean age was significantly different between IDUs and NIDUs; 29.8 (SD 6.7) years for IDUs and 25.5 (SD 5.8) years for NIDUs $(\mathrm{p}<0.001)$. With regard to education levels, about a third of the IDUs and NIDUs had primary or no formal education. Overall, $12.7 \%$ of IDUs and a significantly higher percentage of NIDUs (31.9\%) had migrated to Lashio from another part of Myanmar $(\mathrm{p}<0.001)$.

\section{Factors associated with HIV testing among IDUs}

In total, $76.6 \%$ of IDUs had ever tested for HIV (table 2). Bivariate analysis showed that those who belonged to the older age group (OR 2.57; 95\% CI 1.17 to 5.66) and those who had a regular job (OR 2.91; $95 \%$ CI 1.26 to 6.70 ) were more likely to have tested for HIV. Conversely, IDUs who practiced risky behaviours such as using more than two kinds of drugs (poly drugs; OR $0.40 ; 95 \%$ CI 0.18 to 0.85 ) and injecting drugs at least twice daily (OR $0.41 ; 95 \%$ CI 0.19 to 0.88 ) were less likely to have tested for HIV. Participants who had ever received drug treatment (OR 14.57; 95\% CI 5.82 to 36.47), who had ever registered as a drug user (OR 5.33; 2.25 to 12.62) and who perceived themselves as being at risk of HIV infection (OR 3.57; 95\% CI 1.51 to 8.43) were significantly more likely to have tested for HIV.

The multiple regression model for IDUs indicated that those who were married (AOR 0.24; $95 \%$ CI 0.06 to $0.94)$ and those who injected drugs at least twice daily (AOR $0.30 ; 95 \%$ CI 0.09 to 0.97 ) were less likely to have tested for HIV. Meanwhile, IDUs having a regular job (AOR 4.50; 95\% CI 1.08 to 23.17), who had received drug treatment (AOR 13.07; 95\% CI 3.38 to 50.53) and who perceived themselves as being at risk of contracting HIV (AOR 5.70; 95\% CI 1.40 to 23.25) were more likely to have undergone HIV testing.

\section{Factors associated with HIV testing among NIDUs}

Nearly half of the NIDUs $(45.7 \%)$ had ever tested for HIV (table 3). Being of Shan (OR 0.28; 95\% CI 0.12 to 0.62 ) or Kachin (OR $0.21 ; 95 \%$ CI 0.09 to 0.49 ) ethnicity, reporting poly drug use (OR $0.40 ; 95 \%$ CI 0.21 to $0.74)$, and having visited a female sex worker within the last 3 months (OR $0.50 ; 95 \%$ CI 0.29 to 0.88 ) were negatively associated with HIV testing. Conversely, NIDUs who had ever received drug treatment (OR 2.73; $95 \%$ 
Table 1 Sociodemographic characteristics of participants $(n=368)$

\begin{tabular}{|c|c|c|c|c|c|}
\hline \multirow[b]{2}{*}{ Characteristics } & \multicolumn{2}{|c|}{ IDUs (n=158) } & \multicolumn{2}{|c|}{ NIDUs $(n=210)$} & \multirow[b]{2}{*}{ p Value } \\
\hline & n/mean & Per cent/SD & n/mean & Per cent/SD & \\
\hline Age & 29.8 & 7.2 & 25.5 & 5.8 & $<0.001$ \\
\hline$\leq 20$ & 17 & (10.8) & 40 & $(19.0)$ & \\
\hline $21-30$ & 77 & (48.7) & 134 & (63.8) & \\
\hline $31-40$ & 50 & (31.6) & 30 & (14.3) & \\
\hline $41-50$ & 14 & (8.9) & 6 & $(2.9)$ & \\
\hline Ethnicity & & & & & 0.943 \\
\hline Burma & 35 & (22.2) & 45 & (21.4) & \\
\hline Shan & 46 & (29.1) & 66 & (31.4) & \\
\hline Kachin & 35 & (22.2) & 48 & (22.9) & \\
\hline Others & 42 & (26.5) & 51 & (24.3) & \\
\hline Marital status & & & & & 0.137 \\
\hline Single & 75 & (47.5) & 110 & (52.4) & \\
\hline Married & 66 & (41.8) & 68 & (32.4) & \\
\hline Divorced/widower & 17 & (10.7) & 32 & (15.2) & \\
\hline Education & & & & & 0.227 \\
\hline Primary/no formal education & 52 & (32.9) & 61 & $(29.0)$ & \\
\hline Secondary education & 58 & (36.7) & 67 & (31.9) & \\
\hline High school or above & 48 & (30.4) & 82 & (39.1) & \\
\hline Employment status & & & & & 0.315 \\
\hline Non-regular job & 32 & (20.3) & 34 & $(16.2)$ & \\
\hline Regular job & 126 & (79.7) & 176 & (83.8) & \\
\hline Living status (inter-regional migration) & & & & & $<0.001$ \\
\hline Resident & 138 & (87.3) & 143 & $(68.1)$ & \\
\hline Migrant & 20 & (12.7) & 67 & (31.9) & \\
\hline
\end{tabular}

CI 1.51 to 4.92), had ever registered as a drug user (OR 3.48; $95 \%$ CI 1.61 to 7.49 ) and who perceived themselves at being at risk of HIV infection (OR 3.29; $95 \%$ CI 1.86 to 5.83 ) were more likely to have tested for HIV.

In the multiple regression model for NIDUs, individuals who were of Shan (AOR $0.30 ; 95 \%$ CI 0.11 to 0.84 ) or Kachin (AOR 0.30; $95 \%$ CI 0.10 to 0.87 ) ethnicity and who reported poly drug use within the last 3 months (AOR 0.33; 95\% CI 0.14 to 0.77 ) were less likely to have tested for HIV. Similar results as were observed among IDUs were also observed among NIDUs, viz, NIDUs who had ever received drug treatment (AOR 3.58; 95\% CI 1.38 to 9.24), who had ever registered as a drug user (AOR 4.38; 95\% CI 1.31 to 14.65) and who perceived themselves as being at risk of HIV infection (AOR 4.46; 95\% CI 2.06 to 9.65) were more likely to have tested for HIV.

\section{DISCUSSION}

This is the first study to identify factors associated with HIV testing uptake among IDUs and NIDUs in Lashio, where HIV prevalence among IDUs has been one of the highest in Myanmar. ${ }^{13}$ The HIV testing rate among IDUs was higher compared with that among NIDUs where harm reduction programmes were implemented, especially where such programmes targeted IDUs. Such harm reduction programmes include primary healthcare services, needle and syringe exchange programmes, recreational activities (tea, video, sports and games), and drug/HIV counselling. ${ }^{16}$ Among IDUs, 76.6\% had ever tested for HIV, while $45.7 \%$ of NIDUs had ever tested for HIV. These percentages are much higher compared with the 1-year testing rates reported among Italian drug users: $37.4 \%$ for IDUs and $28 \%$ for NIDUs. ${ }^{17}$ Nonetheless, a comparably high HIV testing rate $(76.2 \%)$ in the last 6 months was reported among Thai IDUs. ${ }^{18}$

HIV testing was positively associated with ever having received drug treatment and with perception of personal risk of HIV infection among both IDUs and NIDUs. IDUs who had a regular job at the time of the survey were also more likely to have undergone HIV testing. Married IDUs and IDUs who injected at least twice daily, meanwhile, were less likely to have undergone HIV testing. Among NIDUs, those who had ever registered as a drug user were more likely to have undergone HIV testing. NIDUs of Shan or Kachin ethnicity and who reported poly drug use within the last 3 months were less likely to have undergone HIV testing.

Notably, both IDUs and NIDUs who had ever received drug treatment were more likely to have been tested for HIV. This finding is in line with studies conducted in similar populations globally. In Vietnam, female sex workers who spent time in a rehabilitation centre were 
Table 2 Factors associated with HIV testing among injecting drug users in Lashio, Myanmar ( $n=158)$

\begin{tabular}{|c|c|c|c|c|c|c|}
\hline & $\mathbf{n}$ & Per cent & OR & $95 \% \mathrm{Cl}$ & AOR & $95 \% \mathrm{Cl}$ \\
\hline \multicolumn{7}{|l|}{ Age } \\
\hline$\leq 29$ & 68 & 43.0 & & & & \\
\hline$>29$ & 90 & 57.0 & 2.57 & 1.17 to $5.66^{*}$ & 2.06 & 0.63 to 6.76 \\
\hline \multicolumn{7}{|l|}{ Marital status } \\
\hline Single & 75 & 47.4 & & & & \\
\hline Married & 66 & 41.8 & 0.61 & 0.28 to 1.35 & 0.24 & 0.06 to $0.94^{*}$ \\
\hline Divorced/widower & 17 & 10.8 & 0.55 & 0.17 to 1.82 & 0.26 & 0.04 to 1.94 \\
\hline \multicolumn{7}{|l|}{ Education } \\
\hline Primary/no formal education & 61 & 29.0 & & & & \\
\hline Secondary education & 67 & 31.9 & 1.57 & 0.64 to 3.86 & 2.59 & 0.63 to 10.60 \\
\hline High school or above & 82 & 39.1 & 1.11 & 0.45 to 2.71 & 1.82 & 0.29 to 4.86 \\
\hline \multicolumn{7}{|l|}{ Ethnicity } \\
\hline Burma & 35 & 22.2 & & & & \\
\hline Shan & 46 & 29.0 & 0.93 & 0.27 to 3.22 & 2.15 & 0.32 to 14.57 \\
\hline Kachin & 35 & 22.2 & 0.22 & 0.07 to $0.71^{*}$ & 0.58 & 0.11 to 2.94 \\
\hline Others & 42 & 26.6 & 0.53 & 0.16 to 1.74 & 0.83 & 0.16 to 4.27 \\
\hline \multicolumn{7}{|l|}{ Employment status } \\
\hline Non-regular job & 32 & 20.3 & & & & \\
\hline Regular job & 126 & 79.7 & 2.91 & 1.26 to $6.70^{*}$ & 4.50 & 1.08 to $23.17^{*}$ \\
\hline \multicolumn{7}{|c|}{ Living status (inter-regional migration) } \\
\hline Migrant & 20 & 12.7 & & & & \\
\hline Resident & 138 & 87.3 & 0.80 & 0.25 to 2.55 & 0.81 & 0.14 to 4.81 \\
\hline \multicolumn{7}{|c|}{ Most used drug type in the last 3 months } \\
\hline Heroin & 156 & 98.7 & $\mathrm{~S} / \mathrm{S}$ & & $\mathrm{S} / \mathrm{S}$ & \\
\hline Stimulant and others & 2 & 1.3 & & & & \\
\hline \multicolumn{7}{|c|}{ Had a history of poly drug use in the last 3 months } \\
\hline Never & 83 & 52.5 & & & & \\
\hline Ever & 75 & 47.5 & 0.40 & 0.18 to $0.85^{*}$ & 0.44 & 0.14 to 1.43 \\
\hline \multicolumn{7}{|c|}{ Had a history of unsafe injection practice in the last 3 months $†$} \\
\hline No & 107 & 52.5 & & & & \\
\hline Yes & 51 & 47.5 & 1.72 & 0.76 to 3.86 & 1.01 & 0.27 to 3.84 \\
\hline \multicolumn{7}{|l|}{ Frequency of injections per day } \\
\hline$\leq 2$ & 86 & 54.4 & & & & \\
\hline$>2$ & 72 & 45.6 & 0.41 & 0.19 to $0.88^{*}$ & 0.30 & 0.09 to $0.97^{\star}$ \\
\hline \multicolumn{7}{|c|}{ Had a history of FSW visit in the last 3 months } \\
\hline Never & 73 & 46.2 & & & & \\
\hline Ever & 85 & 53.8 & 0.74 & 0.35 to 1.56 & 1.34 & 0.25 to 7.12 \\
\hline \multicolumn{7}{|l|}{ Sexual orientation } \\
\hline Heterosexual & 135 & 85.4 & & & & \\
\hline Bisexual/homosexual & 23 & 14.6 & 0.21 & 0.08 to $0.53^{* *}$ & 0.61 & 0.13 to 2.84 \\
\hline \multicolumn{7}{|c|}{ Had more than one partner in the last 3 months } \\
\hline No & 73 & 46.2 & & & & \\
\hline Yes & 85 & 53.8 & 0.40 & 0.18 to $0.89^{\star}$ & 0.20 & 0.04 to 1.11 \\
\hline \multicolumn{7}{|l|}{ Ever received drug treatment } \\
\hline No & 31 & 19.6 & & & & \\
\hline Yes & 127 & 80.4 & 14.57 & 5.82 to $36.47^{\star *}$ & 13.07 & 3.38 to $50.53^{\star * *}$ \\
\hline \multicolumn{7}{|l|}{ Ever registered as a drug user } \\
\hline No & 78 & 49.4 & & & & \\
\hline Yes & 80 & 50.6 & 5.33 & 2.25 to $12.62^{* *}$ & 2.21 & 0.57 to 8.63 \\
\hline \multicolumn{7}{|l|}{ Ever been in prison or jail } \\
\hline No & 106 & 67.1 & & & & \\
\hline Yes & 52 & 32.9 & 0.56 & 0.26 to 1.19 & 0.44 & 0.10 to 1.84 \\
\hline \multicolumn{7}{|l|}{ Perceived HIV risk } \\
\hline No & 90 & 57.0 & & & & \\
\hline Yes & 68 & 43.9 & 3.57 & 1.51 to $8.43^{\star \star}$ & 5.70 & 1.40 to $23.25^{\star}$ \\
\hline
\end{tabular}


Table 3 Factors associated with HIV testing among non-injecting drug usesr in Lashio, Myanmar $(n=210)$

\begin{tabular}{|c|c|c|c|c|c|c|}
\hline & $\mathbf{n}$ & Per cent & OR & $95 \% \mathrm{Cl}$ & AOR & $95 \% \mathrm{Cl}$ \\
\hline \multicolumn{7}{|l|}{ Age } \\
\hline$\leq 25$ & 116 & 55.2 & & & & \\
\hline$>25$ & 94 & 44.8 & 1.17 & 0.68 to 2.02 & 0.75 & 0.33 to 1.71 \\
\hline \multicolumn{7}{|l|}{ Marital status } \\
\hline Single & 110 & 52.4 & & & & \\
\hline Married & 68 & 32.4 & 0.62 & 0.33 to 1.15 & 0.52 & 0.22 to 1.21 \\
\hline Divorced/widower & 32 & 15.2 & 0.88 & 0.40 to 1.94 & 0.39 & 0.13 to 1.18 \\
\hline \multicolumn{7}{|l|}{ Education } \\
\hline Primary/no formal education & 52 & 32.9 & & & & \\
\hline Secondary education & 58 & 36.7 & 2.04 & 1.01 to 4.13 & 2.38 & 0.95 to 5.97 \\
\hline High school or above & 48 & 30.4 & 1.29 & 0.66 to 2.55 & 1.48 & 0.58 to 3.77 \\
\hline \multicolumn{7}{|l|}{ Ethnicity } \\
\hline Burma & 45 & 21.4 & & & & \\
\hline Shan & 66 & 31.4 & 0.28 & 0.12 to $0.62^{*}$ & 0.30 & 0.11 to $0.84^{*}$ \\
\hline Kachin & 48 & 22.9 & 0.21 & 0.09 to $0.49^{\star *}$ & 0.30 & 0.10 to $0.87^{*}$ \\
\hline Others & 51 & 24.3 & 0.43 & 0.19 to 1.00 & 0.52 & 0.18 to 1.49 \\
\hline \multicolumn{7}{|l|}{ Employment status } \\
\hline Non-regular job & 34 & 16.2 & & & & \\
\hline Regular job & 176 & 83.8 & 1.67 & 0.78 to 3.59 & 1.35 & 0.44 to 4.14 \\
\hline \multicolumn{7}{|c|}{ Living status (inter-regional migration) } \\
\hline Migrant & 67 & 31.9 & & & & \\
\hline Resident & 143 & 68.1 & 0.52 & 0.29 to $0.94^{*}$ & 0.55 & 0.26 to 1.17 \\
\hline \multicolumn{7}{|c|}{ Most used drug type in the last 3 months } \\
\hline Heroin & 87 & 41.4 & & & & \\
\hline Stimulant and others & 123 & 58.6 & 1.15 & 0.66 to 2.00 & 1.54 & 0.63 to 3.79 \\
\hline \multicolumn{7}{|c|}{ Had a history of poly drug use in the last 3 months } \\
\hline Never & 58 & 27.6 & & & & \\
\hline Ever & 152 & 72.4 & 0.40 & 0.21 to $0.74^{\star}$ & 0.33 & 0.14 to $0.77^{\star \star}$ \\
\hline \multicolumn{7}{|c|}{ Had a history of FSW visit in the last 3 months } \\
\hline Never & 80 & 38.1 & & & & \\
\hline Ever & 130 & 61.9 & 0.50 & 0.29 to $0.88^{*}$ & 0.63 & 0.30 to 1.33 \\
\hline \multicolumn{7}{|l|}{ Sexual orientation } \\
\hline Heterosexual & 76 & 36.2 & & & & \\
\hline Bisexual/homosexual & 134 & 63.8 & 1.77 & 0.99 to 3.14 & 1.72 & 0.73 to 4.03 \\
\hline \multicolumn{7}{|c|}{ Had more than one partner in the last 3 months } \\
\hline No & 35 & 16.7 & & & & \\
\hline Yes & 175 & 83.3 & 0.87 & 0.42 to 1.80 & 0.80 & 0.27 to 2.38 \\
\hline \multicolumn{7}{|l|}{ Ever received drug treatment } \\
\hline No & 139 & 66.2 & & & & \\
\hline Yes & 71 & 33.8 & 2.73 & 1.51 to $4.92^{\star \star}$ & 3.58 & 1.38 to $9.24^{\star \star}$ \\
\hline \multicolumn{7}{|l|}{ Ever registered as a drug user } \\
\hline No & 173 & 82.4 & & & & \\
\hline Yes & 37 & 17.6 & 3.48 & 1.61 to $7.49^{\star *}$ & 4.38 & 1.31 to $14.65^{\star *}$ \\
\hline \multicolumn{7}{|l|}{ Ever been in prison or jail } \\
\hline No & 174 & 82.9 & & & & \\
\hline Yes & 36 & 17.1 & 1.08 & 0.52 to 2.21 & 1.28 & 0.35 to 4.65 \\
\hline \multicolumn{7}{|l|}{ Perceived HIV risk } \\
\hline No & 120 & 57.1 & & & & \\
\hline Yes & 90 & 42.9 & 3.29 & 1.86 to $5.83^{*}$ & 4.46 & 2.06 to $9.65^{\star \star \star}$ \\
\hline $\begin{array}{l}{ }^{\star} p<0.05 . \\
{ }^{* *} p<0.01 \\
{ }^{* * \star} p<0.001 . \\
A O R, \text { adjusted OR; FSW, female se }\end{array}$ & & & & & & \\
\hline
\end{tabular}

more likely to have tested for HIV. ${ }^{19}$ Moreover, IDUs in Italy who had ever received both pharmacological and psychological treatments were more likely to have tested for HIV than were those who underwent only one kind of treatment. ${ }^{17}$
Drug treatment is playing an important role in reducing the risk of HIV infection among IDUs and NIDUs alike. ${ }^{20}$ However, HIV testing is not currently a compulsory service at drug treatment centres (DTCs) in Myanmar unless a drug user undergoing detoxification 
requests it. Since HIV testing and counselling effectively reduce risk behaviours in drug using populations, the US Centers for Disease Control and Prevention recommends that HIV testing should be integrated into drug treatment services. ${ }^{20}$ Expanding drug treatment to incorporate HIV testing services may also increase the number of IDUs and NIDUs accessing HIV testing services in Myanmar.

In the present study, NIDUs who registered as drug users in the government facilities were more likely to have been tested for HIV. Registering as a drug user is a way to access drug treatment, including MMT and other medical services, at government-run facilities in Myanmar. Following registration, a drug user is scheduled to receive a minimum of 6 weeks' compulsory detoxification. Drug users who fail to register or do not comply with treatment may face a 3-year to 5-year prison sentence. Currently, drug treatment in Myanmar is provided through 26 major DTCs, with a 450 bed capacity per day, and 40 minor DTCs. ${ }^{21}$ Encouraging drug users to register as such may be effective in increasing the uptake of HIV testing services among drug users. Nevertheless, most of the drug users surveyed were reluctant to register their drug use due to several barriers, including stigma towards drug addicts, financial problems, ${ }^{22}$ fear of being known as a drug user, low perceived efficacy of available treatment and the possibility of losing employment opportunities. ${ }^{23} 24$

Among both IDUs and NIDUs, those who had engaged in high-risk behaviours were less likely to have tested for HIV. Additionally, IDUs who injected at least twice daily as well as IDUs and NIDUs who used more than two drugs (poly drug use) were less likely to have been tested for HIV. A similar finding was reported in Thailand, where IDUs who practiced high-risk behaviours were also less likely to undergo HIV testing. ${ }^{18}$ It is not surprising that drug users are more prone to feel reticent to learn of their HIV status through testing due to their risky behaviours, ${ }^{25}$ and to stigma/discrimination related to drug use and its illegality. ${ }^{19}{ }^{26}$ However, injecting drug use is the main mode of HIV transmission in Myanmar, ${ }^{2}{ }^{3}$ and studies indicate that poly drug users are especially likely to practice unsafe sexual behaviours. ${ }^{27}{ }^{28}$ HIV transmission among drug users engaging in risky behaviours might thus be fuelling the HIV epidemic in Myanmar. Hence, HIV testing programmes targeting drug users who exhibit high-risk behaviours are urgently needed, and such programmes might also fruitfully incorporate educational campaigns towards reducing discrimination against drug use.

In this study, perceived risk of HIV infection was a significant predictor for HIV testing among both types of drug users (ie, IDUs and NIDUs). Such individuals may perceive themselves as being at risk of HIV infection after learning of their partner's HIV status, ${ }^{29}$ or they may be compelled to consider the implications of their risky drug use and sexual behaviours, ${ }^{30}$ prompting them to seek HIV counselling and to have their HIV status tested. In this study, we did not confirm participants' HIV status due to ethical considerations. Regardless of HIV status and risk behaviours, however, perceived risk of HIV infection would appear to serve as a selfprotective behaviour which can motivate individuals to practice safer behaviours.

This study showed that IDUs who had a regular job were more likely to have been tested for HIV infection. One possible explanation for this is that the Myanmar National AIDS Programmes have included the workplace as a priority setting for intervention/prevention efforts. ${ }^{31}$ Thus, IDUs with a regular job are likely to have been tested for HIV infection through such programmes. On the other hand, conflicting findings have emerged from studies of Russian IDUs ${ }^{32}$ and tuberculosis patients from Uganda ${ }^{33}$ and Ethiopia. ${ }^{34}$ In these studies, unemployed or part-time workers were more likely to test for HIV than were employed or full-time workers. Further investigation may thus be necessary to explore the impact of employment status on HIV testing behaviours in different contexts.

In the present study, married IDUs were less likely to have been tested for HIV than were single IDUs. This is an important finding, as two-fifths of all new HIV infections in Myanmar occurred through husband-towife transmission in 2010. Moreover, the trend of husband-to-wife transmission is estimated to increase to nearly half of all new infections among women by $2015 .{ }^{35}$ In China, too, married men who have sex with men were less likely to have been tested for HIV than were single men. ${ }^{36}$ Clearly, HIV testing programmes urgently need to focus on encouraging married IDUs to undergo HIV testing.

Another important finding was that NIDUs who were of Shan or Kachin ethnicities were less likely to have been tested for their HIV status than were those of Burma ethnicity. This may be because most of the IEC materials, HIV testing information and HIV counselling services were conducted in the Myanmar language with which the Shan and Kachin ethnicities are not always familiar. Owing to a lack of Myanmar language ability, participants who do not speak or read the Myanmar language may have had difficulty in accessing HIV testing services. Other ethnicities would also benefit if HIV testing services could be conducted in languages representing a broader range of ethnicities such as Shan and Kachin, or if the services could employ staff conversant in the languages of other ethnicities.

Our findings are derived from a cross-sectional study; as such, several possible limitations should be noted in their interpretation. First, HIV testing was self-reported by drug users, and we were not able to confirm their HIV status. Second, our results may not be generalised to drug users in other cities or to drug users who did not participate in this study because they may have characteristics different from those who participated in the study. However, our findings are generally consistent with those of another study from Thailand. ${ }^{18}$ 
Despite their potential limitations, our results present the first look at HIV testing behaviours among drug users in Lashio, Myanmar's famous border trade city, with a high burden of HIV infection. At the same time, further research is needed to understand the barriers and decisions to access HIV testing among drug users, especially for those who are married and engaged in risky behaviours.

\section{CONCLUSIONS}

Both IDUs and NIDUs who had ever received drug treatment were more likely to have tested for HIV in the present study. More IDUs received HIV testing compared with NIDUs. Low HIV testing rates were found among IDUs who were married and who injected at least twice daily and among NIDUs reporting poly drug use within the last 3 months and who were of Kachin or Shan ethnicity. To increase HIV testing rates, especially among NIDUs, we need to encourage them to register as drug users and to provide them with HIV services in the Myanmar language as well as in other ethnic languages. Integrating HIV testing into existing drug treatment programmes and expanding drug treatment services thus emerges as an effective way to increase utilisation of HIV testing among both types of drug users in Myanmar.

Acknowledgements The authors would like to thank all the participants who voluntarily participated in this study and extend their appreciation to Dr Yin Thet Nu Oo and Dr Lin Aung Thu for their support and valuable contributions.

Contributors YMS and JY participated in the design of the study, conducted the statistical analyses and drafted the article. KCP participated in the analysis and interpreted the results. YMS, TNS and ST oversaw the implementation of the study. MJ supervised the study and the revisions to the article. All authors contributed to the writing of the manuscript and approved the final draft.

Funding This study has received funding from the University of Tokyo and from the Ito Foundation for International Education Exchange (G 0114), Tokyo, Japan.

Competing interests None.

Ethics approval The study was approved by the Research Ethics Committee of the Graduate School of Medicine, the University of Tokyo, Tokyo, Japan, and the Institutional Ethical Review Committee, Department of Medical Research (Lower Myanmar), Ministry of Health, Yangon, Myanmar.

Provenance and peer review Not commissioned; externally peer reviewed. Data sharing statement No additional data are available.

\section{REFERENCES}

1. Ministry of Health (MOH), National AIDS Programme. Global AIDS Response Progress Report Myanmar. Myanmar, 2012.

2. Soe ZN. Female Drug Users and Services'Accessibility in Burma (Myanmar): NIDA International Drug Abuse Research Abstract Database, 2010. http://international.drugabuse.gov/meetings/ abstract-database/result/fn\%3D\%2526amp\%3Bln\%3D\%2526amp\% 3Bsub\%3D\%2526amp\%3Byr\%3D0\%2526amp\%3Bcat\%3D0\% 2526amp\%3Bco\%3D0\%2526amp\%3Breg\%3D0\%2526amp\%3Bid\% 3D3067 (accessed 23 May 2012).

3. Aceijas C, Friedman SR, Cooper HL, et al. Estimates of injecting drug users at the national and local level in developing and transitional countries, and gender and age distribution. Sex Transm Infect 2006;82:iii10-17.

4. Sweat M, Gregorich S, Sangiwa G, et al. Cost-effectiveness of voluntary HIV-1 counselling and testing in reducing sexual transmission of HIV-1 in Kenya and Tanzania. Lancet 2000;356:113-21

5. Bernstein E, Heeren T, Winter M, et al. Long-term follow-up after voluntary human immunodeficiency virus/sexually transmitted infection counseling, point-of-service testing, and referral to substance abuse treatment from the emergency department. Acad Emerg Med 2012;19:386-95.

6. Chen HT, Liang S, Liao Q, et al. HIV voluntary counseling and testing among injection drug users in south China: a study of a non-government organization based program. AIDS Behav 2007;11:778-88.

7. Kamb ML, Fishbein M, Douglas JM Jr, et al. Efficacy of risk-reduction counseling to prevent human immunodeficiency virus and sexually transmitted diseases: a randomized controlled trial. Project RESPECT Study Group. JAMA 1998;280:1161-7.

8. Shain RN, Piper JM, Newton ER, et al. A randomized, controlled trial of a behavioral intervention to prevent sexually transmitted disease among minority women. N Engl J Med 1999; 340:93-100.

9. Grusky $\mathrm{O}$, Liu $\mathrm{H}$, Li X, et al. Is voluntary counselling and testing of drug users in China feasible? Int J STD AIDS 2006;17:354-5.

10. UNAIDS. Fund for HIV/AIDS in Myanmar: Annual Progress Report, 2006-2007. The Joint United Nations Programme on HIV/AIDS, Myanmar, 2007.

11. Thwe M. Service coverage for HIV and AIDS in Myanmar. The 8th International Congress on AIDS in Asia and the Pacific (ICAAP). Colombo, Sri Lanka, 2007.

12. Qian HZ, Schumacher JE, Chen HT, et al. Injection drug use and HIV/AIDS in China: review of current situation, prevention and policy implications. Harm Reduct J 2006;3:4.

13. Ministry of Health (MOH), National AIDS Programme, Myanmar. Behavioral Surveillance Survey among Injecting Drug Users and Female Sex Workers. 2008.

14. Heckathorn DD. Respondent-driven sampling: a new approach to the study of hidden populations. Soc Probl 1997;44:174-99.

15. De Maere W, Singh S, Tun T, et al. Rapid assessment and action research on drug use and HIV in Lashio, Northern Shan State, Myanmar: Asian Harm Reduction Network, Myanmar (AHRN-Myanmar). 2006.

16. Asian Harm Reduction Network (AHRN). Annual Performance Report, Myanmar, 2005.

17. Camoni L, Federico B, Capelli G, et al. Few Italian drug users undergo HIV testing. AIDS Behav 2011;15:711-17.

18. Ti L, Hayashi K, Kaplan K, et al. HIV testing and willingness to get HIV testing at a peer-run drop-in centre for people who inject drugs in Bangkok, Thailand. BMC Public Health 2012;13:189.

19. Grayman JH, Nhan DT, Huong PT, et al. Factors associated with HIV testing, condom use, and sexually transmitted infections among female sex workers in Nha Trang, Vietnam. AIDS Behav 2005;9:41-51.

20. Centers for Disease Control and Prevention (CDC). Linking HIV prevention services and substance abuse treatment programs, 2002.

21. DevaneyReid M, Baldwin G S. Situational analysis of illicit drug issues and responses in the Asia-Pacific region. Burnet Institute's Centre for Harm Reduction and Turning Point Alcohol and Drug Centre, 2006.

22. Appel PW, Ellison AA, Jansky HK, et al. Barriers to enrollment in drug abuse treatment and suggestions for reducing them: opinions of drug injecting street outreach clients and other system stakeholders. Am J Drug Alcohol Abuse 2004;30:129-53.

23. Bobrova N, Rhodes T, Power R, et al. Barriers to accessing drug treatment in Russia: a qualitative study among injecting drug users in two cities. Drug Alcohol Depend 2006;82:S57-63.

24. Tucker JA. Resolving problems associated with alcohol and drug misuse: understanding relations between addictive behavior change and the use of services. Subst Use Misuse 2001;36:1501-18

25. Spielberg F, Kurth A, Gorbach PM, et al. Moving from apprehension to action: HIV counseling and testing preferences in three at-risk populations. AIDS Educ Prev 2001;13:524-40.

26. Hayashi K, Milloy MJ, Fairbairn N, et al. Incarceration experiences among a community-recruited sample of injection drug users in Bangkok, Thailand. BMC Public Health 2009;30:492.

27. Patterson TL, Semple SJ, Zians JK, et al. Methamphetamine-using HIV-positive men who have sex with men: correlates of polydrug use. J Urban Health 2005;82:i120-6.

28. Fernández MI, Bowen GS, Varga LM, et al. High rates of club drug use and risky sexual practices among Hispanic men who have sex with men in Miami, Florida. Subst Use Misuse 2005; 40:1347-62. 
29. Adih WK, Alexander CS. Determinants of condom use to prevent HIV infection among youth in Ghana. J Adolesc Health 1999;24:63-72.

30. Filipe EM, Batistella E, Pine A, et al. Sexual orientation, use of drugs and risk perception among HIV-positive men in Sao Paulo, Brazil. Int J STD AIDS 2005;16:56-60.

31. Ministry of Health (MOH), National AIDS Programme, Myanmar. UNGASS Country Progress Report Myanmar, 2010.

32. Niccolai LM, Toussova OV, Verevochkin SV, et al. High HIV prevalence, suboptimal HIV testing, and low knowledge of HIV-positive serostatus among injection drug users in St. Petersburg, Russia. AIDS Behav 2010;14:932-41.
33. Sendagire I, Schreuder I, Mubiru M, et al. Low HIV testing rates among tuberculosis patients in Kampala, Uganda. BMC Public Health 2010;10:177.

34. Jerene D, Endale A, Lindtjorn B. Acceptability of HIV counselling and testing among tuberculosis patients in south Ethiopia. BMC Int Health Hum Rights 2007;7:4.

35. Myat K. Rise in husband-to-wife HIV infections expected: NGOs. The Myanmar Times, 2010. http://www.mmtimes.com/2010/news/ 545/54515news.html (accessed 23 May 2012).

36. Wei C, Ruan S, Zhao J, et al. Which Chinese men who have sex with men miss out on HIV testing? Sex Transm Infect 2011;87:225-8. 